\title{
Alkylating DNA damage stimulates a regulated form of necrotic cell death
}

\author{
Wei-Xing Zong, ${ }^{1}$ Dara Ditsworth, ${ }^{1}$ Daniel E. Bauer, ${ }^{1}$ Zhao-Qi Wang, ${ }^{2}$ and Craig B. Thompson ${ }^{1,3}$ \\ ${ }^{1}$ Abramson Family Cancer Research Institute, Department of Cancer Biology, University of Pennsylvania, Philadelphia, \\ Pennsylvania 19104, USA; ${ }^{2}$ Unit of Gene-Environment Interactions, International Agency for Research on Cancer (IARC), \\ 69008 Lyon, France
}

Necrosis has been considered a passive form of cell death in which the cell dies as a result of a bioenergetic catastrophe imposed by external conditions. However, in response to alkylating DNA damage, cells undergo necrosis as a self-determined cell fate. This form of death does not require the central apoptotic mediators p53, Bax/Bak, or caspases and actively induces an inflammatory response. Necrosis in response to DNA damage requires activation of the DNA repair protein poly(ADP-ribose) polymerase (PARP), but PARP activation is not sufficient to determine cell fate. Cell death is determined by the effect of PARP-mediated $\beta$-nicotinamide adenine dinucleotide (NAD) consumption on cellular metabolism. Cells using aerobic glycolysis to support their bioenergetics undergo rapid ATP depletion and death in response to PARP activation. In contrast, cells catabolizing nonglucose substrates to maintain oxidative phosphorylation are resistant to ATP depletion and death in response to PARP activation. Because most cancer cells maintain their ATP production through aerobic glycolysis, these data may explain the molecular basis by which DNA-damaging agents can selectively induce tumor cell death independent of p53 or Bcl-2 family proteins.

[Keywords: Alkylating DNA damage; necrosis; PARP; metabolism; Bax; Bak; p53]

Received March 3, 2004; revised version accepted April 9, 2004.

Cell death plays an important role in development, tissue homeostasis, and degenerative diseases. Two major forms of cell death have been described: apoptosis and necrosis. Apoptosis, also called programmed cell death, is an energy-driven process by which a cell actively destroys itself in response to extracellular signals or developmental cues, whereas necrosis has been considered a passive process in which a cell dies as a result of bioenergetic catastrophe. Apoptosis is characterized by the ordered cellular degradation of proteins and organelles, maintenance of plasma membrane integrity, and noninflammatory phagocytosis of the dying cell (Wang 2001; Adams 2003). During necrosis, cells swell rapidly and lose the integrity of their plasma membrane, releasing cellular contents into the extracellular environment, and triggering an acute inflammatory response. Necrosis has traditionally been considered an unregulated form of cell death, and has been well characterized in a wide range of pathologic states including ischemia, trauma, and infection (Majno and Joris 1995; Kanduc et al. 2002). A great deal of recent attention has focused on the role of apoptosis in normal development and various disease processes. Most if not all cancer cells have defects in the

${ }^{3}$ Corresponding author.

E-MAIL craig@mail.med.upenn.edu; FAX (215) 746-5511.

Article published online ahead of print. Article and publication date are at http://www.genesdev.org/cgi/doi/10.1101/gad.1199904. normal control of apoptosis. The first characterized example of this is the $14: 18$ chromosomal translocation found in patients with follicular lymphoma that juxtaposes the immunoglobulin enhancer with the antiapoptotic gene bcl-2 (Tsujimoto et al. 1984). Enhanced expression of $\mathrm{Bcl}-2$ provides resistance to apoptosis by suppressing the activation of the proapoptotic Bcl-2related proteins Bax and Bak. Bax and Bak are essential in apoptosis initiated from both mitochondria and the endoplasmic reticulum (ER). Cells lacking both Bax and Bak are resistant to apoptosis induced by developmental cues, signal transduction through death receptors, growth factor withdrawal, and ER stress (Lindsten et al. 2000; Cheng et al. 2001; Wei et al. 2001; Zong et al. 2001, 2003; Degenhardt et al. 2002b; Scorrano et al. 2003).

Despite the role of Bcl-2 as an antiapoptotic protein, follicular lymphoma cells are sensitive to treatment with DNA-alkylating drugs in vivo (Lister 1991). To address how it is that cells resistant to apoptosis die in response to such treatment, we studied the ability of these agents to induce death in cells deficient in both Bax and Bak $\left(\mathrm{bax}^{-/-} \mathrm{bak}^{-/-}\right)$or deficient in p53. In response to alkylating DNA damage, both $\mathrm{bax}^{-/-} \mathrm{bak}^{-/-}$ and $p 53^{-/-}$cells die by necrosis. Although enzymatic activation of the DNA repair protein poly(ADP-ribose) polymerase (PARP) is required for this form of necrotic 
cell death, the cell fate in response to a DNA-alkylating agent is determined by cellular metabolic status. Thus, there exists an intrinsic cellular control point that determines cell fate in response to PARP activation. Together, these results demonstrate that PARP-mediated necrosis is a regulated cell fate.

\section{Results}

Alkylating agents induce cell death independent of apoptotic effectors

Mouse embryo fibroblasts (MEFs) generated from wildtype, $p 53^{-/-}$, and $b_{a x}^{-/-} b a k^{-/-}$animals were tested for sensitivity to the alkylating agents mechlorethamine hydrochloride (nitrogen mustard) and N-methyl-N'-nitro$\mathrm{N}$-nitrosoguanidine (MNNG), as well as to the kinase inhibitor staurosporine and the DNA topoisomerase inhibitor etoposide. Staurosporine induced cell death in wild-type and $\mathrm{p}^{-/-}$cells, but not in $\mathrm{bax}^{-/-} \mathrm{bak}^{-/-}$cells (Fig. 1A). Both $\mathrm{bax}^{-/-} \mathrm{bak}^{-/-}$and $\mathrm{p53^{-/- }}$ cells were resistant to etoposide treatment (Fig. 1B). In contrast, both $\mathrm{bax}^{-/-} \mathrm{bak}^{-/-}$and $\mathrm{p} 53^{-/-}$cells were as sensitive as wildtype cells to nitrogen mustard and MNNG (Fig. 1C,D). These findings indicate that DNA alkylation initiates cell death in a manner that is independent of the apoptotic initiators p53 or Bax/Bak. Additional experiments confirmed that neither overexpression of the antiapoptotic protein $\mathrm{Bcl}-\mathrm{x}_{\mathrm{L}}$ nor addition of the caspase inhibitors zVAD and BAF could inhibit cell death induced by MNNG (data not shown).

\section{Activation of PARP and depletion of NAD and ATP in response to DNA damage}

DNA alkylation has been shown to activate the enzymatic activity of PARP, which catalyzes the synthesis of poly(ADP-ribose) polymers on histones and other chro- matin-associated proteins in the vicinity of the DNA adduct (D'Amours et al. 1999). This process promotes the efficient recognition of the DNA damage by DNA repair enzymes. Because $\beta$-nicotinamide adenine dinucleotide (NAD) is the substrate for poly/ADP-ribosyl)ation, PARP activation has been shown to deplete cellular NAD and contribute to cell death in response to excitotoxic stimuli or reperfusion injury (Szabo and Dawson 1998; Pieper et al. 1999b). We tested whether PARP activation is involved in death of $\mathrm{bax}^{-/-} \mathrm{bak}^{-/-}$ cells in response to DNA damage. Upon MNNG treatment, PARP was activated equally in wild-type and $\mathrm{bax}^{-/-} \mathrm{bak}^{-/-}$cells, as indicated by the increase of poly(ADP-ribose) polymers (PAR; Fig. 2A). MNNG treatment also caused a dose-dependent decrease in NAD and ATP in both wild-type and $b_{a x}{ }^{-/} b_{a k}^{-/-}$cells. This depletion could be prevented by the nicotinic acid analog DPQ, which among other functions acts in vitro as a PARP inhibitor (Fig. 2B,C).

\section{DNA damage-induced necrosis is PARP-dependent}

The above findings suggest that DNA-alkylating agents can trigger the PARP-dependent depletion of NAD and ATP in cells, and this process is independent of the mitochondrial apoptosis pathway. To test directly if PARP is required to initiate NAD/ATP depletion and cell death in response to MNNG, shRNA was used to suppress the expression of PARP-1, which accounts for $\sim 90 \%$ of the PARP activity among the PARP family members (Smith 2001). Among the stable $\mathrm{bax}^{-/-} \mathrm{bak}^{-/-}$MEF clones transfected with an shRNA vector, Clone HP17 demonstrated a dramatic reduction of PARP-1 expression, whereas in Clone HP11 the PARP-1 level was moderately decreased (Fig. 3A). Correlating with the levels of PARP-1 expression, poly(ADP-ribosyl)ation was moderately decreased in clone HP11 upon MNNG treatment, and significantly decreased in clone HP17 (Fig. 3B). The remaining poly-
A
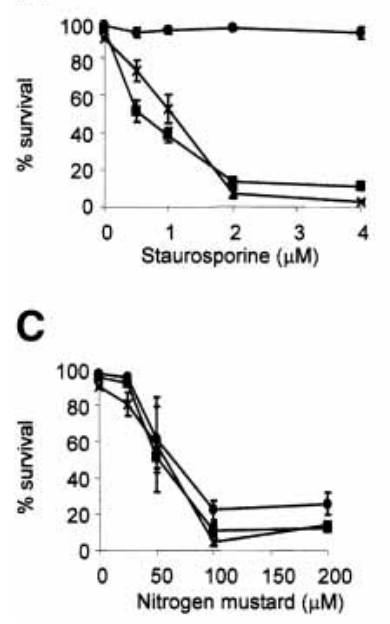

B

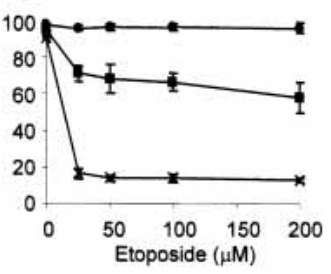

D

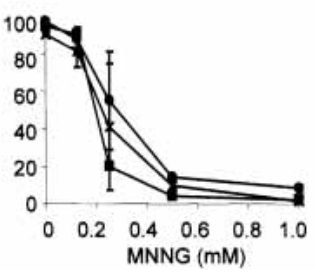

Figure 1. Cells deficient in p53 or Bax/Bak are susceptible to DNA-alkylating agents. MEFs from wild-type, $\mathrm{p} 53^{-/-}$, and $b a x^{-/-} b a k^{-/-}$mice were treated with staurosporine $(A)$, etoposide $(B)$, nitrogen mustard $(C)$, and MNNG $(D)$ as described in Materials and Methods. Drug concentrations are indicated in the individual panels. Cell survival was determined for triplicate samples by PI exclusion at $20 \mathrm{~h}$ following treatment. Data are presented as mean \pm S.D. and are representative of three independent experiments. 
A

Figure 2. Alkylating DNA damage results in PARP activation and bioenergetic collapse. (A) MNNG activates PARP in both wild-type and $b a x^{-/-} b a k^{-/-}$cells. Wild-type and $b a x^{-/-} b_{a k}^{-/-}$MEFs were treated with MNNG $(0.5 \mathrm{mM})$ for the indicated periods of time. Cells were lysed and immunoblotting was performed using an antibody against poly(ADP-ribose) (PAR). The asterisk marks a nonspecific band. $(B, C)$ Depletion of NAD and ATP in response to PARP activation. Wild-type and $\mathrm{bax}^{-1-} \mathrm{bak}^{-/-}$cells were treated with MNNG at indicated concentrations for 30 min, alone or together with PARP inhibitor DPQ. The cellular NAD $(B)$ and ATP (C) levels were determined. Concentrations of NAD and ATP were normalized with that of untreated cells.

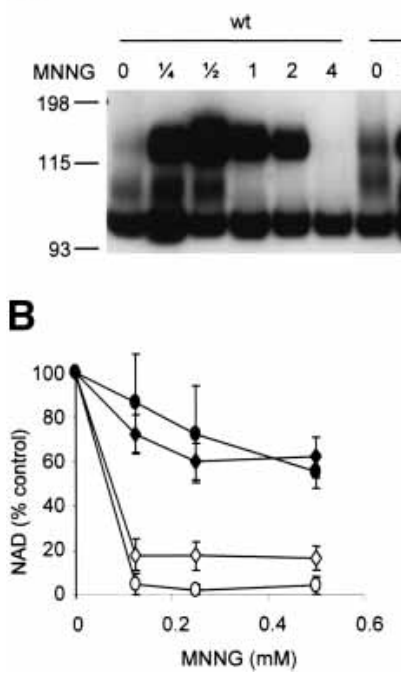

bax- - -bak- -1

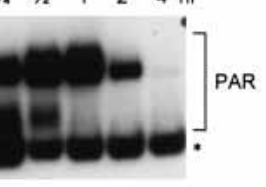

C

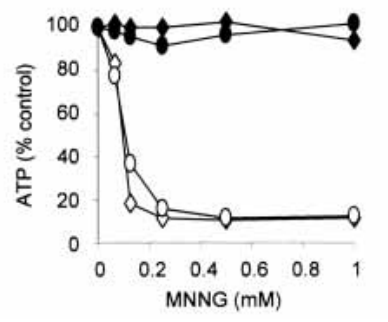

$-\infty$ wt MNNG

$\rightarrow-w t$ MNNG+DPQ

-a-bax- $/$-bak- - MNNG

$\rightarrow$ bax - -bak $\%$ MNNG+DPQ
(ADP-ribosyl)ation may result from minimal residual PARP-1 that could not be detected by immunoblotting, or from the activation of other PARP family members (Smith 2001). Despite the residual PARP activity in Clone HP17, ATP levels were maintained upon MNNG treatment (Fig. 3C). Importantly, no cell death was observed in clone HP17 when treated with MNNG at concentrations that killed all vector control $b a x^{-/-} b a k^{-/-}$ cells (Fig. 3D).

In contrast to $\mathrm{bax}^{-/-} \mathrm{bak}^{-/-}$cells, the death of wildtype cells was only partially rescued by PARP inhibitor DHIQ, suggesting that DNA alkylators can induce more than one death pathway. To test this further, wild-type, bax ${ }^{-/-}$bak $^{-/-}$, parp-1 $1^{-/-}$(Wang et al. 1995), and Clone HP17 $\left(b_{a x}{ }^{-/} b a k^{-/-}\right.$, shPARP-1) cells were compared side by side for sensitivity to different death stimuli (Fig. $3 \mathrm{E}, \mathrm{F})$. All wild-type and $b a x^{-/-} b_{a k^{-/-}}$cells died within $20 \mathrm{~h}$ following $0.5 \mathrm{mM}$ MNNG treatment. In contrast, only $30 \%$ of similarly treated parp-1 $1^{-/-}$cells died, and HP17 cells showed essentially no cell death (Fig. 3E,F). The reduced cell density observed resulted from the growth arrest effect caused by DNA alkylation. Wildtype and parp-1 $1^{-/-}$cells were killed by staurosporine, whereas no cell death was observed in $b a x^{-/-} b a k^{-/-}$and clone HP17 cells (Fig. 3F). The PARP-inhibitor DHIQ blocked cell death partially in wild-type cells, and fully in $b a x^{-/-} b a k^{-1-}$ cells. DHIQ did not affect the cell death rate in parp $-^{-/-}$cells (Fig. 3F). Although additional MNNG-treated parp-1-1- cells underwent apoptosis over the next several days in culture, $>30 \%$ of cells treated with $0.25 \mathrm{mM}$ MNNG were alive $3 \mathrm{~d}$ after the treatment, and almost $90 \%$ of HP17 cells remained viable (Fig. 3G). Taken together, these findings indicate that two independently regulated death pathways can be triggered in response to alkylating DNA damage. One is mediated via the Bax/Bak mitochondrial gateway, accounting for the cell death observed in parp-1-1- cells and the DHIQinsensitive death in the other cells. The other form of death is mediated by PARP activation and is Bax/Bakindependent.

\section{Cell death in the absence of Bax and Bak is necrotic}

To test if PARP-dependent cell death in response to DNA-alkylating agents was distinguishable from apoptosis, morphologic features of the cell death in response to MNNG and staurosporine were characterized by electron microscopy. Both wild-type and $b a x^{-/-} b_{a k}{ }^{-/-}$cells acquired morphologic changes characteristic of necrosis upon MNNG treatment. These included organelle swelling, intracellular vacuole formation, plasma membrane disintegration, and nuclear degradation without condensation (Fig. 4A). In addition, some wild-type cells displayed an intermediate morphology with both apoptotic and necrotic features. In contrast, staurosporine induced apoptotic morphological changes in wild-type cells including condensed chromatin and no obvious disintegration of the cell body. Although staurosporine treatment induced some nonspecific changes in the appearance of $b a x^{-/-} b a k^{-/-}$cells, apoptotic features were not observed and the cells remained viable (Fig. 4A).

A central event in apoptosis is the release of apoptogenic factors such as cytochrome $c$ from the mitochondrial intermembrane space into the cytosol. In $b_{a x}{ }^{-/-}$ $b a k^{-/-}$cells treated with MNNG, no change of cytochrome $c$ distribution pattern was observed, although the cells had undergone cell death as indicated by shrinkage of nuclei (Fig. 4B). In addition, $b_{a x}{ }^{-/-} b a k^{-/-}$cells displayed none of the biochemical apoptotic hallmarks tested, including caspase cleavage of PARP-1 and lamin B1 (Fig. 4C). It is interesting to note that in wild-type cells, treatment with MNNG resulted in some cells acquiring apoptotic features. Cytochrome $c$ release was observed in some cells (Fig. 4B), and a decrease in the caspase substrates PARP-1 and lamin B1 observed in the population as a whole (Fig. 4C). Furthermore, the 
A

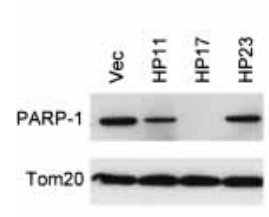

C

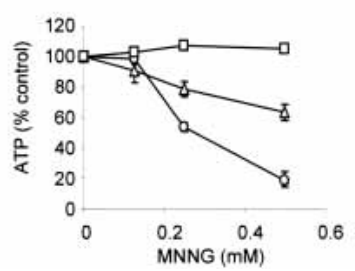

E

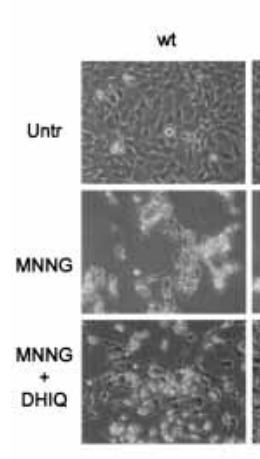

$\mathbf{F}$

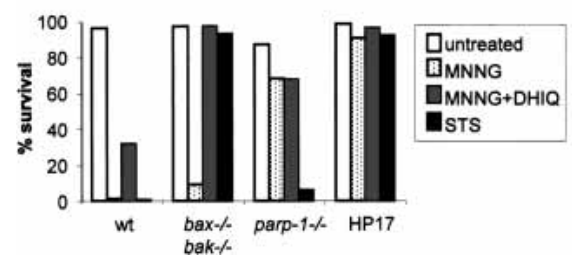

B

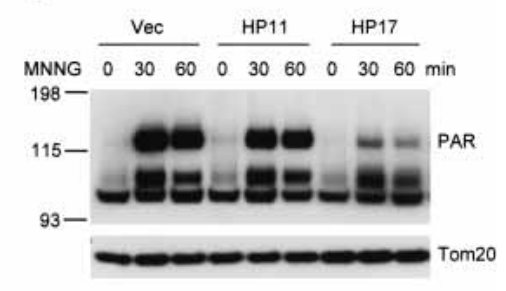

D

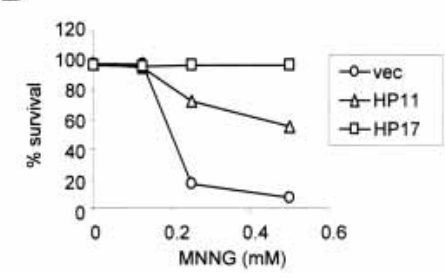

Figure 3. PARP inhibition results in resistance to MNNG-induced cell death. (A) PARP-1 shRNA in $\mathrm{bax}^{-/-} \mathrm{bak}^{-/-}$cells. Stable clones were selected from $b_{a x}{ }^{-1} b_{a k}{ }^{-1-}$ MEFs transfected with vector or PARP-1 hairpins. Cell lysates were made from a vector cell line or PARP-1 hairpin cell lines. Immunoblotting was performed using an anti-PARP-1 antibody, and an anti-Tom 20 antibody as a control for equal loading. Note that PARP-1 expression was suppressed significantly in Clone HP17, moderately in HP11, and not affected in HP23. (B) PARP activity was determined using triplicate samples by immunoblotting using an anti-PAR antibody. (C) ATP levels were measured after $30 \mathrm{~min}$ of treatment with MNNG at the indicated concentrations. $(D)$ Cell survival was determined by PI exclusion $20 \mathrm{~h}$ after MNNG treatment. $(E, F)$ Wild-type, $\mathrm{bax}^{-/-} \mathrm{bak}^{-1-}$, parp-1-1-, and Clone HP17 $\left(\mathrm{bax}^{-1-} \mathrm{bak}^{-/-}\right.$, shPARP-1) MEFs were treated with MNNG $(0.5 \mathrm{mM})$ alone or together with PARP inhibitor DHIQ, or in the presence of staurosporine (STS). Twenty-four hours later, cells were photographed under a phase-contrast filter $(E)$, and cell survival was determined by PI exclusion $(F)$. $(G)$ Wild-type, bax ${ }^{-/-}$bak $^{-/-}$, parp$1^{-/-}$, and Clone HP17 MEFs were treated with MNNG (0.25 mM). Cell survival was measured over time by PI exclusion.

caspase-cleaved forms of PARP-1 and lamin B1 were observed in the wild-type population primarily in the presence of PARP inhibitors (Fig. 4C). This indicated that MNNG may trigger both necrotic and apoptotic responses in wild-type cells. The apoptotic component of the death is not dependent on PARP, because the apoptotic features persisted when PARP inhibitors DHIQ and DPQ were applied (Fig. 4B,C).

\section{PARP-mediated cell death is proinflammatory}

Apoptotic cells die in an ordered fashion, and are engulfed and cleared in vivo, whereas necrotic cells lose their membrane integrity and release the cellular contents into the extracellular environment triggering an acute inflammatory response. One of the proinflammatory molecules reported to be released into the extracel- lular environment during necrotic cell death is HMGB1, a chromatin-associated protein that if released from cells acts as a ligand for the monocyte/macrophage scavenger receptor RAGE (Scaffidi et al. 2002). MNNG-treated cells were evaluated for HMGB1 localization. In untreated cells, HMGB1 localized to the nucleus. However, $6 \mathrm{~h}$ following treatment of MNNG, there was translocation of HMGB1 from the nucleus to the cytosol (Fig. 5A). This redistribution was active, as it began prior to observable cell death. By $16 \mathrm{~h}$ after MNNG treatment, HMGB1 could be found in the extracellular environment. HMGB1 redistribution and release were blocked when PARP was inhibited (Fig. 5B). To determine if the release of factors such as HMGB1 is sufficient to induce an inflammatory response in innate immune cells, cell culture medium was collected and added to cultured macrophages. Macrophage activation was assessed by 
Zong et al.

A
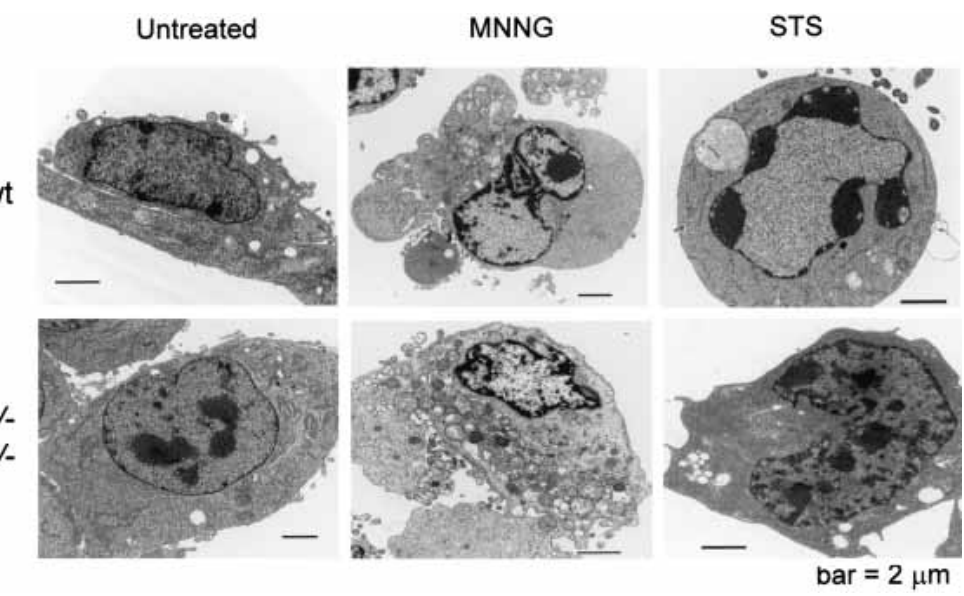

B

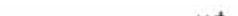

wt
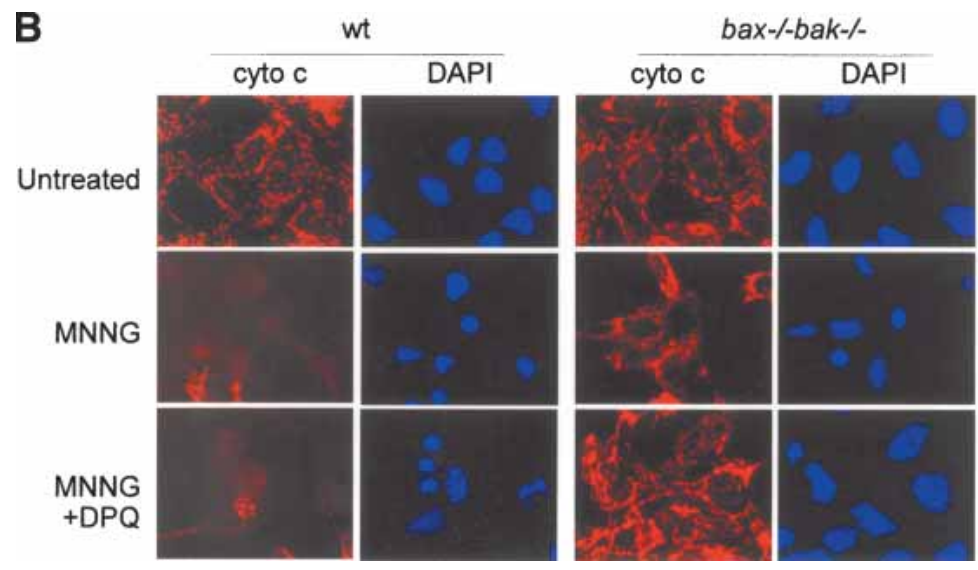

C

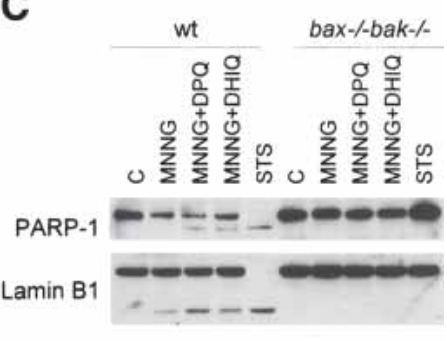

Figure 4. PARP-mediated cell death is necrotic. (A) Wild-type and $b a x^{-/-} b a k^{-/-}$cells were treated with $0.5 \mathrm{mM} \mathrm{MNNG}$, or $2 \mu \mathrm{M}$ staurosporine (STS). Transmission electron microscopy was performed $9 \mathrm{~h}$ later. (B) Transformed wild-type baby mouse kidney (BMK) cells were treated with MNNG alone or together with DPQ. Immunofluorescence was performed $6 \mathrm{~h}$ later using an antibody against cytochrome $c$. Cells were counterstained with DAPI to show the nuclear morphology. (C) Wild-type and bax ${ }^{-/-}$bak ${ }^{-/-}$MEFs were treated with indicated agents. Cells were lysed after $8 \mathrm{~h}$, and $20 \mu \mathrm{g}$ of protein was separated on a $4 \%-12 \%$ gradient NuPAGE gel. PARP and Lamin B1 were detected using respective antibodies.

the production of the proinflammatory cytokine TNF $\alpha$. Culture medium from MNNG-treated wild-type and $\mathrm{bax}^{-/-} \mathrm{bak}^{-/-}$cells induced TNF $\alpha$ production, whereas medium harvested from apoptotic cells (wild-type and parp $-1^{-/-}$treated with staurosporine) failed to do so (Fig. 5C). Taken together, these findings indicate that MNNG induces necrotic cell death, and that the dying cell actively establishes its ability to release inflammatory mediators upon death.

\section{Proliferating cells are more sensitive to PARP-mediated necrosis}

In vivo, chemotherapeutic agents selectively induce the death of tumor cells and normal cells undergoing cell division (DeVita 1997). We next investigated whether MNNG-induced cell death might account for such selectivity. Because both apoptotic and necrotic death pathways can be activated by DNA damage, we took advantage of $b_{a x}^{-/-} b a k^{-1-}$ cells to study PARP-mediated necrosis without interference from apoptosis. Interleukin-3 (IL-3)-dependent bax ${ }^{-/-} b_{a k}{ }^{-/-}$cells were used. Upon IL-3 deprivation, these cells withdraw from the cell cycle but remain viable. The $\mathrm{bax}^{-/-} \mathrm{bak}^{-/-}$cells proliferating in response to IL-3 were killed by MNNG in a dose-dependent manner. In contrast, IL-3-deprived $\mathrm{bax}^{-/-} \mathrm{bak}^{-/-}$cells were resistant to MNNG (Fig. 6A). Furthermore, this protection was not transient. When IL-3 was added to the IL-3-dependent cultures $24 \mathrm{~h}$ after $0.5 \mathrm{mM}$ MNNG treatment, cells recovered and cell viability in the culture $48 \mathrm{~h}$ later was reproducibly $>85 \%$. In contrast, the viability of cells treated with $0.5 \mathrm{mM}$ MNNG in the presence of IL-3 continued to decline over the first $72 \mathrm{~h}$ after treatment. Similarly, we observed that MEFs grown to confluence and then serum-deprived were less sensitive to MNNG-induced cell death than subconfluent MEFs cultured in the presence of serum (Fig. 6B). This suggested that growth factor signal transduction and/or cell cycle commitment might contribute to sensitivity to PARP-mediated necrosis. To determine whether the decreased susceptibility of nonproliferating 


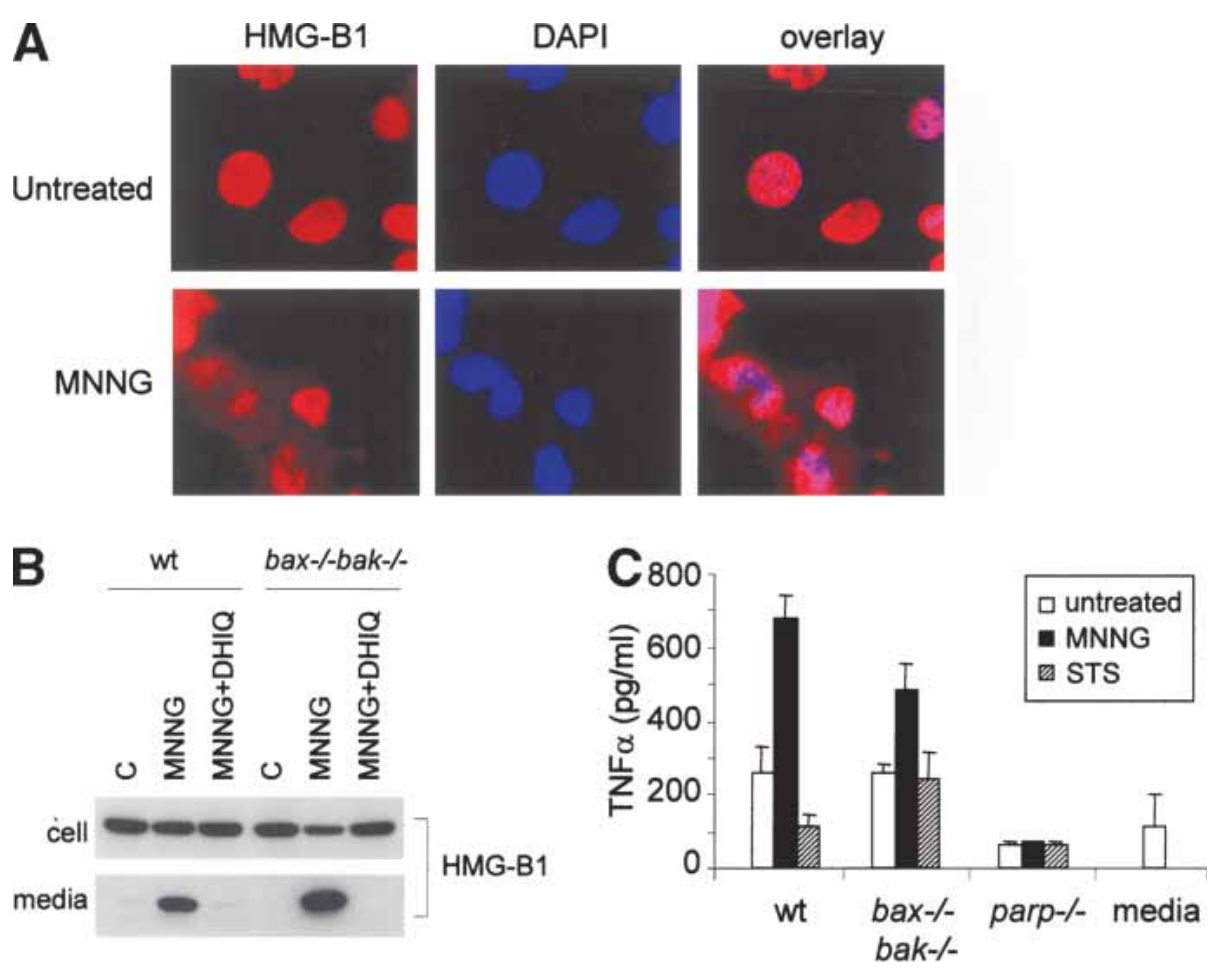

Figure 5. PARP-mediated cell death is proinflammatory. (A) HMGB1 translocates from nucleus into cytosol upon MNNG treatment. $\mathrm{bax}^{-/-} \mathrm{bak}^{-/-} \mathrm{MEF}$ were treated with $0.5 \mathrm{mM}$ MNNG. Six hours later, immunofluorescence was performed using an antibody against HMGB1. Nuclei were visualized by DAPI staining. (B) HMGB1 is released into extracellular environment during MNNG-induced necrosis. Wild-type and $b a x^{-/-} b a k^{-/-}$MEFs were treated with $0.5 \mathrm{mM}$ MNNG alone or together with DPQ. Culture media were collected $16 \mathrm{~h}$ later, and cells were lysed in RIPA buffer. HMGB1 was detected by immunoblotting in both cell lysates and culture media. $(C)$ Inflammatory response triggered by necrosis. Wild-type, bax ${ }^{-1-}$ bak ${ }^{-/-}$, or parp-1 $1^{-/-}$MEFs were treated with MNNG $(0.5$ $\mathrm{mM}$ ) for $15 \mathrm{~min}$ or STS $(2 \mu \mathrm{M})$ for $2 \mathrm{~h}$. Drugs were washed away and cells were refed with fresh media. Twenty hours later, cell culture media were collected and added to $1 \times 10^{5}$ macrophages. Concentration of TNF $\alpha$ was measured $24 \mathrm{~h}$ later.

cells to MNNG is caused by impaired activation of PARP, PARP activation was determined. Equivalent increases in poly(ADP-ribosyl)ation were observed in vegetative and proliferating cells (Fig. 6C). Based on assaying isolated DNA for strand breaks, equivalent amounts of DNA damage were observed in cells growing in the presence or absence of IL-3 (data not shown). Consistent with the increase of poly(ADP-ribosyl)ation, cellular NAD level was decreased to a similar extent under both culture conditions (Fig. 6D). However, whereas the total cellular ATP level was drastically decreased in cells cultured in the presence of IL-3, the ATP level was preserved in the cells deprived of IL-3 $(p<0.01$; Fig. $6 \mathrm{D})$.

Two major ATP-generation mechanisms exist in a cell involving NAD utilization: one through glycolysis using cytosolic NAD as a substrate, and another by mitochondrial oxidative phosphorylation via the $\mathrm{F}_{1} \mathrm{~F}_{0}$-ATP synthase. Thus, NAD consumption by PARP would be predicted to have a differential effect on glycolysis and oxidative phosphorylation because cytosolic NAD and mitochondrial NAD do not exchange with each other. Consistent with this, subcellular fractionation showed that whereas MNNG treatment reduced cytosolic NAD to minimal levels, mitochondrial NAD was not significantly affected (Fig. 6E).

\section{PARP-mediated necrosis is controlled by cellular metabolic status}

The cytosolic and mitochondrial NAD pools are used in different pathways to generate ATP, namely, glycolysis and oxidative phosphorylation, respectively. The finding that PARP preferentially depletes cytosolic NAD suggested that cells sensitive to PARP might depend on glucose metabolism for ATP production. Consistent with this model, IL-3-treated cells were found to be highly glycolytic (Fig. 7A), and inhibition of oxidative phosphorylation did not affect the ATP level of these cells (Fig. 7B). In contrast, IL-3-deprived cells displayed a low glycolytic rate (Fig. 7A; Gonin-Giraud et al. 2002), and ATP levels fell dramatically when oxidative phosphorylation was inhibited with oligomycin (Fig. 7B). Together, these data suggest that growth factor status affects glycolytic rate and the predominant means of ATP production.

In IL-3-stimulated cells, ATP falls when cytosolic NAD is depleted (Fig. 6D). This suggests that these cells are unable to increase oxidative phosphorylation to maintain ATP when NAD depletion compromises the ability to carry out glycolysis. A potential explanation for this is that in response to IL-3-induced growth, cells 
Zong et al.

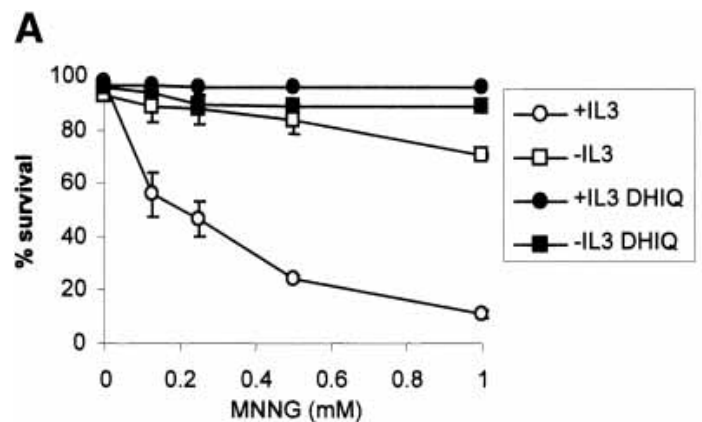

B

C

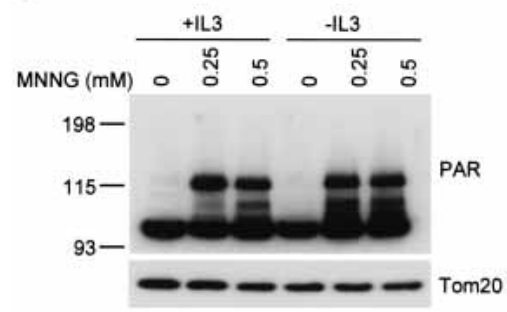

D
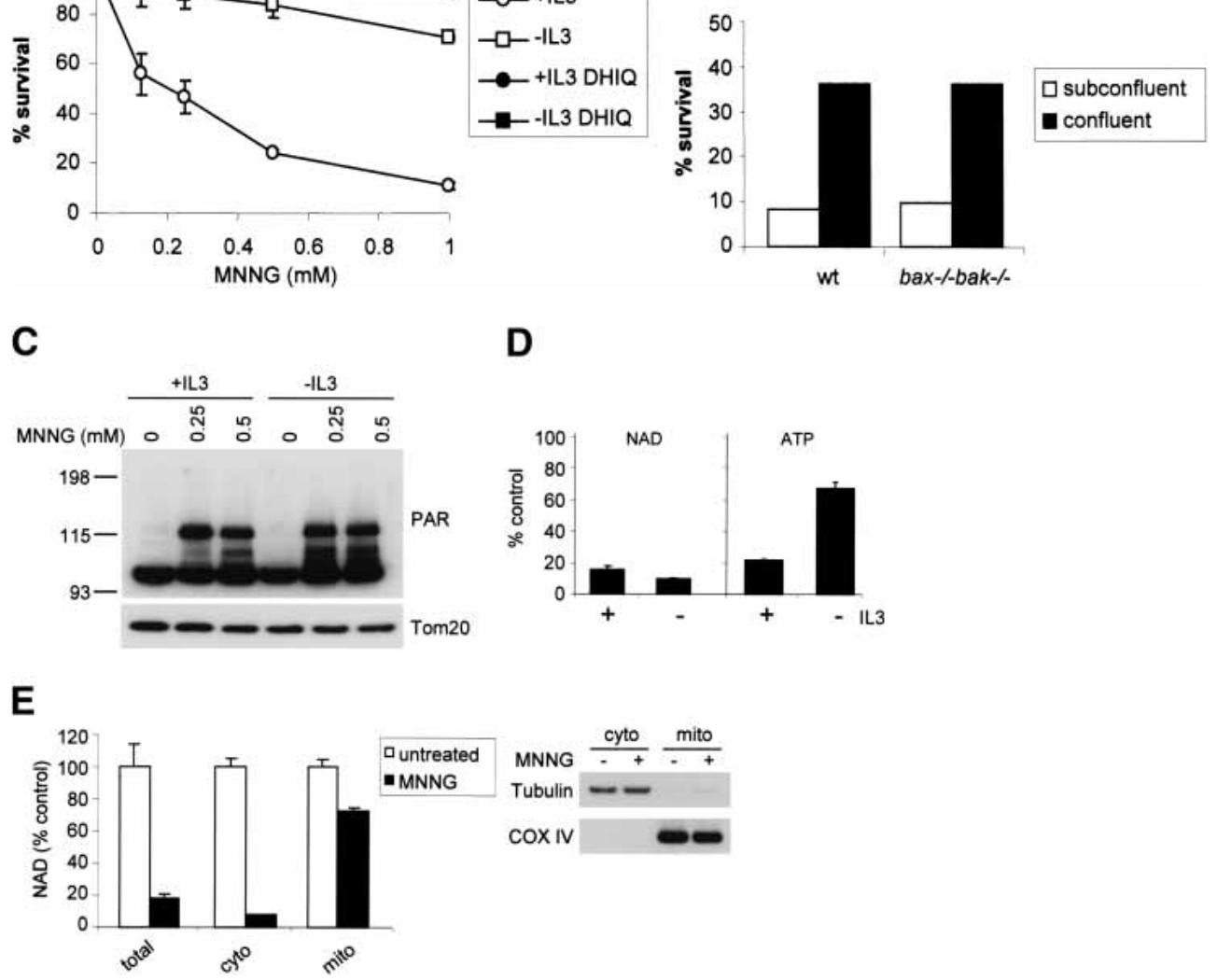

Figure 6. Vegetative cells are more resistant to PARP-mediated necrosis. (A) IL-3-dependent hematopoietic $b_{a x}{ }^{-/-} b_{a k}{ }^{-/-}$cells were cultured in media with or without IL-3 for $2 \mathrm{~d}$. Cells were treated with MNNG for 15 min at indicated concentrations, and cell survival was measured by PI exclusion $24 \mathrm{~h}$ later. (B) Wild-type and $b a x^{-/-} b_{a k}{ }^{-/-}$MEFs were plated at $2 \times 10^{4} /$ well (subconfluent) or $2 \times 10^{5} /$ well (confluent) in 12-well plates. Cells were cultured for $36 \mathrm{~h}$. Confluent cells were then cultured in the absence of serum for $12 \mathrm{~h}$ and subconfluent cells were cultured in the presence of serum. Cells were treated with $0.5 \mathrm{mM}$ MNNG for 15 min. Cell survival was determined $24 \mathrm{~h}$ later by PI exclusion. $(C, D)$ IL-3-dependent $b a x^{-1-} b a k^{-1-}$ cells were cultured in the presence or absence of IL-3 for 2 d. Cells were then treated with MNNG for 15 min. PARP activity was determined by immunoblotting of PAR, and NAD and ATP levels were measured and shown as the percentage of the levels in untreated cells. Cellular NAD pool was decreased in both proliferating and vegetative cells $(C)$, whereas the cellular ATP pool was preserved in vegetative cells but not in proliferating cells $(D)$. (E) PARP activation preferentially depletes cytosolic NAD. IL-3-dependent cells were treated with $0.5 \mathrm{mM}$ MNNG for 15 min. Cells were fractionated and the NAD levels were measured in total cell lysates, as well as in the cytosolic and mitochondrial fractions. Immunoblotting of tubulin and COX IV were performed to assure the purity of the fractionation.

shunt amino acids and lipids away from ATP-generating oxidative metabolism and into synthetic pathways. Under conditions of declining extracellular glucose availability, IL-3-stimulated cells can up-regulate mitochondrial fatty acid oxidation to generate ATP, a process not dependent on cytosolic NAD. To determine whether this might have a protective effect, we withdrew IL-3treated cells from glucose $>48 \mathrm{~h}$ before treatment with MNNG. When IL-3-stimulated cells were adapted to low glucose, they displayed resistance to MNNG-induced death that was comparable to that of IL-3-deprived cells (Fig. 7C). Thus IL-3 signal transduction alone is not sufficient to confer sensitivity to MNNG-induced cell death.

Finally, to determine if PARP-induced death occurs as a result of glycolytic blockade, we tested whether PARP- induced necrosis could be suppressed by supplying the cells with the glycolytic end product pyruvate. $b_{a x}{ }^{-/-}$ $b_{a k^{-/-}}$cells growing in the presence of IL-3 were supplemented with $10 \mathrm{mM}$ methyl-pyruvate, a membrane-permeable form of pyruvate, and then treated with MNNG. Methyl-pyruvate supplementation rendered IL-3-stimulated $b_{a x}{ }^{-/-} b a k^{-/-}$cells as resistant to MNNG-induced cell death as IL-3-deprived cells (Fig. 7C). Thus, cells using substrates that are catabolized in the mitochondria to maintain ATP production are resistant to MNNGinduced necrosis. To demonstrate that the resistance to MNNG-induced necrosis was not a peculiar event in $b a x^{-/-} b a k^{-/-}$cells, cells with wild-type Bax and Bak were preincubated with methyl-pyruvate before MNNG treatment. Similar to $b a x^{-/-} b a k^{-/-}$cells, methyl-pyruvate treatment of cells with wild-type Bax and Bak also 
A

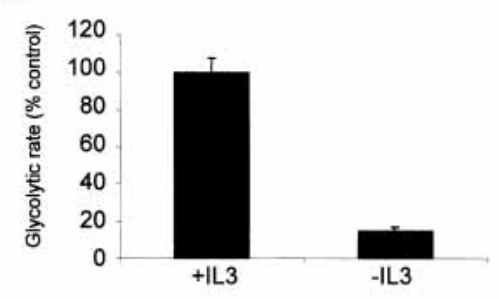

C

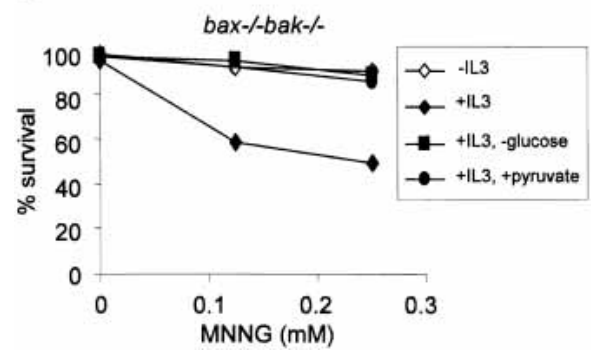

B

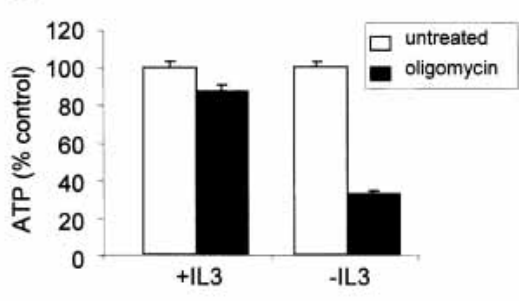

D

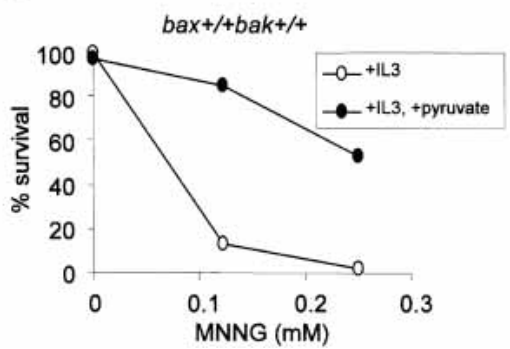

Figure 7. Susceptibility to PARP-mediated necrosis is controlled by cellular metabolic status. (A) Cellular glycolysis rate in the presence or absence of IL-3. IL3 -dependent $\mathrm{bax}^{-/-} \mathrm{bak}^{-1-}$ cells were cultured in the presence or absence of IL-3 for $2 \mathrm{~d}$. One million cells were harvested and their glycolysis rate was determined. $(B)$ Effect of inhibition of oxidative phosphorylation on ATP levels in cells cultured with or without IL-3. Cells cultured in media with or without IL-3 were treated with oligomycin $(5 \mu \mathrm{g} / \mathrm{mL})$ for 30 min, and ATP levels were determined. $(C)$ IL-3-dependent $\mathrm{bax}^{-1-} \mathrm{bak}^{-1-}$ cells cultured in the presence or absence of IL-3 for 2 d. An additional population was cultured in the presence of IL-3 in complete medium made without glucose (-glucose), whereas a fourth population was cultured in the presence of IL-3 and supplemented with $10 \mathrm{mM}$ methyl-pyruvate (+pyruvate) immediately prior to MNNG treatment. Cells were then treated with MNNG, and cell survival was determined by PI exclusion as described in Materials and Methods. The data presented are representative of three independent experiments. (D) Methyl-pyruvate (10 mM) was added to the IL-3-dependent wild-type cells immediately prior to MNNG treatment. Cells were treated with MNNG and cell survival was determined by PI exclusion.

increased their resistance to MNNG-induced cell death (Fig. 7D). Thus, cellular metabolic status does not only determine the cell fate in Bax/Bak-null background, but also contributes to the regulation of cell fate in cells capable of undergoing Bax/Bak-dependent apoptosis in response to DNA damage.

\section{Discussion}

Programmed cell death has been defined as cell suicide in response to developmental cues or intrinsic cell stress. The major form of programmed cell death described to date is apoptosis. Apoptotic cell death is ATP-dependent, results in organized proteolytic degradation of the intracellular contents, and phagocytosis of the dying cell without inducing an inflammatory response. In this report, we describe a form of cell death in which the cell actively initiates its own necrosis in response to alkylating DNA damage. This form of cell death is independent of the major apoptotic effectors p53, Bax, Bak, and caspases.

In response to DNA damage, cells activate PARP, an enzyme that catalyzes poly(ADP-ribosyl)ation of a variety of proteins (D'Amours et al. 1999). This activity of PARP can increase the accessibility of DNA to DNA repair enzymes and transcription factors. There has been controversy concerning the role of PARP in the regulation of cell survival/death in response to DNA damage. Some work has implicated PARP in the regulation of DNA repair and cell survival (Wang et al. 1997), whereas others have implicated PARP in initiating cell death by either apoptosis (Yu et al. 2002) or necrosis (Ha and Snyder 1999). Our results help to clarify these issues. Here we show that activation of PARP runs a metabolic test on the damaged cell. In cells that maintain their ATP production exclusively by catabolizing glucose, PARP activation results in a rapid decline in cellular ATP and necrotic death. In contrast, in cells that can maintain non-glucose-dependent oxidative phosphorylation, PARP activation does not compromise cellular bioenergetics and such cells are resistant to DNA damageinduced death.

The cellular test run by PARP provides a potential explanation for the ability of DNA-alkylating drugs to act as effective chemotherapeutic agents. In general, it is believed that most chemotherapeutic drugs induce tumor cells to die by apoptosis. However, a central feature of perhaps all cancers is the development of apoptotic resistance. The most common genetic abnormality in human tumors is mutation of p53. Loss of p53 function is associated with pronounced apoptotic resistance (Vousden and Lu 2002; Gudkov and Komarova 2003). Nevertheless, alkylating agents remain the single most effective and broadly active chemotherapeutic agents (Chabruer and Longo 2001). It is thought that the efficacy of alkylating drugs results from the selective ability to kill proliferating cells. Proliferating cells have been shown to have an increased propensity to apoptosis under some circumstances (Evan and Vousden 2001). However, the discovery that neither Bax/Bak deficiency nor p53 deficiency is required to affect cell death in response to DNA damage suggested that there might be alternative explanations for the ability of alkylating agents to selectively kill tumor cells. One such explanation may be PARP-mediated necrosis. It will be of interest to determine whether tumors resistant to DNA alkylating agents have acquired loss of or altered PARP activity.

Tumor cells display an abnormal propensity for 
growth and are in net protein and lipid synthesis. As a result, they maintain ATP production almost exclusively through catabolizing glucose through a mixture of glycolysis and oxidative phosphorylation termed aerobic glycolysis (Holt 1983; Baggetto 1992). In contrast, cells that are not actively growing or replicating are capable of catabolizing a variety of metabolic substrates to maintain ATP production (Eaton et al. 1996). Inhibition of the mitochondrial respiratory chain has been shown to induce death of vegetative cells (Hartley et al. 1994; Woodgate et al. 1999; Ohgoh et al. 2000). In contrast, mitochondrial inhibitors do not affect the viability of cells with a high-level glycolytic rate because they are capable of maintaining ATP levels without mitochondrial respiration (Shchepina et al. 2002). By differentially affecting ATP generation from glycolysis or mitochondrial respiration, our results demonstrate that activation of PARP can selectively kill cells that are preferentially maintaining their bioenergetics through glycolysis. Based on the data presented above, it is the proliferating cell's dependency on aerobic glycolysis that determines its sensitivity to PARP-induced cell death. The data presented here raise the possibility that the alkylating drugs are effective not because they activate apoptosis in their target cells but because they induce a tumor-selective form of necrosis.

This necrotic form of programmed cell death may be adaptive as it both eliminates the possibility of cell survival and induces an immune response to the dying cell. In response to DNA damage, there is an active redistribution of the macrophage activator HMGB1 from the nucleus to the cytosol (Fig. 4A; Muller et al. 2001). HMGB1 is a small acidic protein localized to chromatin primarily by electrostatic forces (Butler et al. 1985). As histones and other chromatin proteins are modified by poly(ADP-ribosyl)ation, the resulting increase in negative charge may displace HMGB1, thus releasing it from the chromatin. This, in turn, will increase HMGB1 release into the extracellular environment if the cell loses plasma membrane integrity during necrotic death. In contrast, HMGB1 has been shown to have increased affinity for the DNA fragments created during apoptosis (Scaffidi et al. 2002). This increased sequestration of HMGB1 suppresses its ability to be released from the cell during apoptosis. PARP-dependent release of proinflammatory mediators such as HMGB1 distinguishes programmed necrosis from apoptosis. The ability of alkylating agent-induced necrosis to induce an inflammatory response to the dying tumor cells may contribute to the efficacy of the drugs as chemotherapeutic agents. Consistent with an important role for PARP-mediated necrosis in inflammatory responses, parp-1 $1^{-/-}$mice are resistant to ischemia-reperfusion (Eliasson et al. 1997), endotoxic shock (Szabo et al. 1996), and streptozotocininduced diabetes (Burkart et al. 1999; Masutani et al. 1999; Pieper et al. 1999a).

In summary, the above data demonstrate that necrosis can be a regulated cell fate independent of apoptosis. Necrotic cell death following DNA damage occurs selectively in cells committed to growth. This prevents the survival of cells at risk of accumulating mutations as a result of DNA replication prior to DNA repair. In addition, this form of programmed necrosis induces an inflammatory response that provides additional protection against the accumulation of damaged or aberrant cells, and initiates the repair of the damaged tissue.

\section{Materials and methods}

\section{Cell culture and cell death assay}

MEFs and BMK cells were cultured as described (Zong et al. 2001; Degenhardt et al. 2002a). IL-3-dependent $\mathrm{bax}^{-/-} \mathrm{bak}^{-/-}$ cells were cultured in RPMI 1640 supplemented with 10\% FBS, $2 \mathrm{mM}$ glutamine, $1 \%$ penicillin/streptomycin, $20 \mathrm{mM}$ HEPES, $50 \mu \mathrm{M} 2$-mercaptoethanol, supplemented with $4 \mathrm{ng} / \mathrm{mL}$ recombinant mouse IL-3 (BD-Pharmingen). IL-3-dependent FL5.12 cells were cultured in the same media as used for $\mathrm{bax}^{-1-} \mathrm{bak}^{-/-}$ cells, supplemented with $0.4 \mathrm{ng} / \mathrm{mL}$ recombinant mouse IL-3. To induce cell death with MNNG (Sigma), cells were treated with MNNG for $15 \mathrm{~min}$. Cells were washed and fed with fresh medium with no MNNG, and cultured for indicated periods of time. For etoposide (Calbiochem), staurosporine (Sigma), and mechlorethanmine hydrochloride (nitrogen mustard; Sigma) treatment, the agents remained in the medium. PARP inhibitors DPQ or DHIQ (Sigma) were kept in the medium throughout the course of experiment when used. At the end of experiments, propidium iodide (PI, $1 \mathrm{\mu g} / \mathrm{mL}$; Molecular Probes) was added to the cells. Cell death was determined using flow cytometry by PI exclusion.

\section{Immunoblotting and immunofluorescence}

Cells were lysed in RIPA buffer ( $1 \%$ Sodium Deoxycholine, $0.1 \%$ SDS, $1 \%$ Triton $\mathrm{X}-100,10 \mathrm{mM}$ Tris at $\mathrm{pH} 8.0,0.14 \mathrm{M}$ $\mathrm{NaCl}$ ) with protease inhibitor complex (Roche). Twenty micrograms of protein was loaded on a precast $4 \%-12 \%$ NuPAGE gel. Western blotting was performed with the following antibodies: PARP (clone C2-10; BD-Pharmingen or Trevigen), Lamin B1 (M20; Santa Cruz), Tom20 (FL-145; Santa Cruz), PAR (BD-Pharmingen), COX IV (Molecular Probes), Tubulin (Sigma), and HMGB1 (BD-Pharmingen). For immunofluorescence, cells were fixed in $4 \%$ paraformaldehyde and permeabilized for $10 \mathrm{~min}$ in PBS containing $0.2 \%$ Triton X-100. Cells were washed with PBS containing $0.02 \%$ Triton X-100 and $1.5 \%$ FBS, followed by incubation with antibodies against Bax (6A7; BD-Pharmingen), cytochrome $c$ (BD-Pharmingen), or HMGB1 for $1 \mathrm{~h}$ at room temperature. Cells were incubated with Rhodamine-conjugated secondary antibody (Jackson ImmunoResearch). Nuclei were visualized by staining with $1 \mu \mathrm{g} / \mathrm{mL}$ DAPI. Images were captured on a 510 LSM confocal microscope (Zeiss).

\section{Determination of NAD and ATP}

The concentration of NAD was measured as described (Jacobson and Jacobson 1976) with modification. Briefly, $1 \times 10^{5}$ cells were trypsinized and resuspended in $100 \mu \mathrm{L}$ of $0.5 \mathrm{M}$ perchloric acid. Cell extracts were neutralized with equal volume of $1 \mathrm{M} \mathrm{KOH}$ and $0.33 \mathrm{M} \mathrm{KH}_{2} \mathrm{PO}_{4} / \mathrm{K}_{2} \mathrm{HPO}_{4}(\mathrm{pH} 7.5)$. After centrifugation to remove the $\mathrm{KClO}_{4}$ precipitate, $200 \mu \mathrm{L}$ of NAD reaction mixture (600 mM ethanol, $0.5 \mathrm{mM}$ 3-[4,5 dimethylthiazol-2-yl]-2,5 diphenyltetrazolium bromide [MTT], $2 \mathrm{mM}$ phenazine ethosulfate, $5 \mathrm{mM}$ EDTA, $1 \mathrm{mg} / \mathrm{mL}$ BSA, $120 \mathrm{mM}$ bicine at $\mathrm{pH} 7.8$ ) was added to $50 \mu \mathrm{L}$ of the supernatant or NAD standard and incubated for $5 \mathrm{~min}$ at $37^{\circ} \mathrm{C}$. Twenty-five microliters of alcohol de- 
hydrogenase $(0.5 \mathrm{mg} / \mathrm{mL}$ in $100 \mathrm{mM}$ bicine at $\mathrm{pH} 7.8)$ was added to the reaction and incubated for $20 \mathrm{~min}$ at $37^{\circ} \mathrm{C}$. To stop the reaction, $250 \mu \mathrm{L}$ of $12 \mathrm{mM}$ iodoacetate was added, and the O.D. was read at $570 \mathrm{~nm}$ wavelength. Protein concentration was determined using BCA protein assay reagents (Pierce). The content of NAD was normalized by protein content. For ATP determination, $2 \times 10^{4}$ cells were lysed in a cell lysis reagent (cata$\log \# 1699709$; Boehringer Mannheim). ATP concentration was determined as previously described (Vander Heiden et al. 1999).

\section{Transmission electronic microscopy}

Cells were rinsed with serum-free DMEM medium, and fixed with prewarmed $2.5 \%$ glutaraldehyde, $2 \%$ formaldehyde in 0.1 $\mathrm{M}$ sodium cacodylate buffer for $1 \mathrm{~h}$. Cells were washed, postfixed with $2 \%$ osmium tetroxide, dehydrated with ascending grades of ethanol and propylene oxide, and embedded in LX-112 medium (Ladd). After polymerization, ultrathin $(90 \mathrm{~nm}) \mathrm{sec}-$ tions were cut with a diamond knife, collected on uncoated copper grids, and stained with uranyl acetate $(1 \%)$ and lead citrate $(0.2 \%)$. Samples were examined with a JEOL-1010 electron microscope (JEOL) operated at $80 \mathrm{kV}$.

\section{$\operatorname{sh} R N A$}

A forward oligonucleotide with the sequence from an RNA Polymerase III-specific U6 promoter CAGTGGAAAGACGCG CAGGCA, and a reverse oligonucleotide AAAAAAGGAAGTG AAAGCGGCCAACGTTCCTCGAGCAACGTTGGCCGCTT TCACTTCCGTGTTTCGTCCTTTCCACAA that contains a hairpin of the PARP-1 transcript sequence and sequence from the U6 promoter, were used in a PCR to generate a DNA fragment that allows the transcription of the PARP-1 hairpin under the control of the U6 promoter. This DNA cassette was cloned into a pBabe-puro-based retroviral vector. The control vector or PARP-1 hairpin constructs were transfected into MEFs using Lipofectamine 2000 transfection reagent (Invitrogen). Single cell clones were propagated using limited dilution, and screened for their PARP-1 expression.

\section{TNF $\alpha$ measurement}

Mouse bone-marrow-derived macrophages were generated as described (Myung et al. 2000). In all, $5 \times 10^{5} \mathrm{MEFs}$ were plated in six-well plates, and treated with MNNG for 15 min or staurosporine for $2 \mathrm{~h}$. Cells were washed and refed with $1 \mathrm{~mL}$ of fresh culture media. Sixteen hours later, the cell culture media were collected and added to $1 \times 10^{5}$ macrophages/well plated in 96-well plates a day earlier. TNF $\alpha$ production was measured 24 h later using a Quantikine TNF $\alpha$ ELISA kit (R\&D Systems).

\section{Subcellular fractionation}

IL-3-dependent cells were suspended in hypotonic Buffer A (250 $\mathrm{mM}$ sucrose, $20 \mathrm{mM}$ HEPES at $\mathrm{pH} 7.5,10 \mathrm{mM} \mathrm{KCl}, 1.5 \mathrm{mM}$ $\mathrm{MgCl}_{2}, 1 \mathrm{mM}$ EDTA, $1 \mathrm{mM}$ EGTA, $1 \times$ protease inhibitor complex [Roche]). Subcellular fractionation was carried out as previously described (Zong et al. 2003). The resulting cytosolic fraction was used directly for NAD measurement, protein quantification, and immunoblotting. The mitochondrial pellet was divided into two equal parts; one was lysed in $0.5 \mathrm{mM} \mathrm{HClO}_{4}$ and used for NAD measurement, and another part was lysed in RIPA buffer for protein quantification and immunoblotting.

\section{Measurement of glycolysis}

The cellular glycolysis rate was determined as described (Liang et al. 1997) with modifications. One million cells were incu- bated with $10 \mu \mathrm{Ci} 5{ }^{3} \mathrm{H}$-glucose (PerkinElmer Life Sciences) for $1 \mathrm{~h}$ at $37^{\circ} \mathrm{C}$. Following incubation, the reaction was stopped with $0.2 \mathrm{~N} \mathrm{HCl}$, and ${ }^{3} \mathrm{H}_{2} \mathrm{O}$ was separated from $5-{ }^{3} \mathrm{H}$-glucose by diffusion in an airtight container. Diffused and undiffused tritium was measured using a 1450 Microbeta scintillation counter (Wallac) and compared with controls of $5-^{3} \mathrm{H}$-glucose only and ${ }^{3} \mathrm{H}_{2} \mathrm{O}$ only to determine the rate of glycolysis.

\section{Acknowledgments}

We thank Dr. Eileen White for BMK cells, Dr. Qian-Chun Yu for assistance with electron microscopy, Dr. Kim Nichols for help with macrophage cell culture, and Ryan Cinalli for help with designing shRNA hairpins. We thank Tullia Lindsten, David Plas, Monica Buzzai, Rebecca Elstrom, Ralph DeBerardinis, Julian Lum, and the rest of the Thompson laboratory for reagents and discussions. W.X.Z. is supported by postdoctoral fellowships from the Cancer Research Institute and the Leukemia and Lymphoma Society.

The publication costs of this article were defrayed in part by payment of page charges. This article must therefore be hereby marked "advertisement" in accordance with 18 USC section 1734 solely to indicate this fact.

\section{References}

Adams, J.M. 2003. Ways of dying: Multiple pathways to apoptosis. Genes \& Dev. 17: 2481-2495.

Baggetto, L.G. 1992. Deviant energetic metabolism of glycolytic cancer cells. Biochimie 74: 959-974.

Burkart, V., Wang, Z.Q., Radons, J., Heller, B., Herceg, Z., Stingl, L., Wagner, E.F., and Kolb, H. 1999. Mice lacking the poly(ADP-ribose) polymerase gene are resistant to pancreatic $\beta$-cell destruction and diabetes development induced by streptozocin. Nat. Med. 5: 314-319.

Butler, A.P., Mardian, J.K., and Olins, D.E. 1985. Nonhistone chromosomal protein HMG 1 interactions with DNA. Fluorescence and thermal denaturation studies. I. Biol. Chem. 260: 10613-10620.

Chabruer, B.A. and Longo, D.L. 2001. Cancer chemotherapy and biotherapy: Principles and practices. Lippincott Williams and Wilkins, Philadelphia.

Cheng, E.H., Wei, M.C., Weiler, S., Flavell, R.A., Mak, T.W., Lindsten, T., and Korsmeyer, S.J. 2001. BCL-2, BCL-X(L) sequester $\mathrm{BH} 3$ domain-only molecules preventing BAX- and BAK-mediated mitochondrial apoptosis. Mol. Cell 8: 705711.

D'Amours, D., Desnoyers, S., D'Silva, I., and Poirier, G.G. 1999. Poly(ADP-ribosyl)ation reactions in the regulation of nuclear functions. Biochem. J. 342 (Pt 2): 249-268.

Degenhardt, K., Chen, G., Lindsten, T., and White, E. 2002a. BAX and BAK mediate p53-independent suppression of tumorigenesis. Cancer Cell 2: 193-203.

Degenhardt, K., Sundararajan, R., Lindsten, T., Thompson, C., and White, E. 2002b. Bax and Bak independently promote cytochrome c release from mitochondria. J. Biol. Chem. 277: 14127-14134.

DeVita, V.T. 1997. Principles of cancer management: Chemotherapy. In Cancer: Principles and practice of oncology (eds. V.T. DeVita et al.), pp. 333-347. Lippincott-Raven, Philadelphia.

Eaton, S., Bartlett, K., and Pourfarzam, M. 1996. Mammalian mitochondrial $\beta$-oxidation. Biochem. J. 320 (Pt 2): 345-357.

Eliasson, M.J., Sampei, K., Mandir, A.S., Hurn, P.D., Traystman, 
R.J., Bao, J., Pieper, A., Wang, Z.Q., Dawson, T.M., Snyder, S.H., et al. 1997. Poly(ADP-ribose) polymerase gene disruption renders mice resistant to cerebral ischemia. Nat. Med. 3: 1089-1095.

Evan, G.I. and Vousden, K.H. 2001. Proliferation, cell cycle and apoptosis in cancer. Nature 411: 342-348.

Gonin-Giraud, S., Mathieu, A.L., Diocou, S., Tomkowiak, M., Delorme, G., and Marvel, J. 2002. Decreased glycolytic metabolism contributes to but is not the inducer of apoptosis following IL-3-starvation. Cell Death Differ. 9: 1147-1157.

Gudkov, A.V. and Komarova, E.A. 2003. The role of p53 in determining sensitivity to radiotherapy. Nat. Rev. Cancer 3: $117-129$.

Ha, H.C. and Snyder, S.H. 1999. Poly(ADP-ribose) polymerase is a mediator of necrotic cell death by ATP depletion. Proc. Natl. Acad. Sci. 96: 13978-13982.

Hartley, A., Stone, J.M., Heron, C., Cooper, J.M., and Schapira, A.H. 1994. Complex I inhibitors induce dose-dependent apoptosis in PC12 cells: Relevance to Parkinson's disease. J. Neurochem. 63: 1987-1990.

Holt, J.A. 1983. Cancer, a disease of defective glucose metabolism. Med. Hypotheses 10: 133-150.

Jacobson, E.L. and Jacobson, M.K. 1976. Pyridine nucleotide levels as a function of growth in normal and transformed 3T3 cells. Arch. Biochem. Biophys. 175: 627-634.

Kanduc, D., Mittelman, A., Serpico, R., Sinigaglia, E., Sinha, A.A., Natale, C., Santacroce, R., Di Corcia, M.G., Lucchese, A., Dini, L., et al. 2002. Cell death: Apoptosis versus necrosis (review). Int. J. Oncol. 21: 165-170.

Liang, Y., Buettger, C., Berner, D.K., and Matschinsky, F.M. 1997. Chronic effect of fatty acids on insulin release is not through the alteration of glucose metabolism in a pancreatic $\beta$-cell line ( $\beta$ HC9). Diabetologia 40: 1018-1027.

Lindsten, T., Ross, A.J., King, A., Zong, W.X., Rathmell, J.C., Shiels, H.A., Ulrich, E., Waymire, K.G., Mahar, P., Frauwirth, K., et al. 2000. The combined functions of proapoptotic Bcl-2 family members bak and bax are essential for normal development of multiple tissues. Mol. Cell 6: 13891399.

Lister, T.A. 1991. The management of follicular lymphoma. Ann. Oncol. 2 Suppl 2: 131-135.

Majno, G. and Joris, I. 1995. Apoptosis, oncosis, and necrosis. An overview of cell death. Am. J. Pathol. 146: 3-15.

Masutani, M., Suzuki, H., Kamada, N., Watanabe, M., Ueda, O., Nozaki, T., Jishage, K., Watanabe, T., Sugimoto, T., Nakagama, H., et al. 1999. Poly(ADP-ribose) polymerase gene disruption conferred mice resistant to streptozotocin-induced diabetes. Proc. Nat1. Acad. Sci. 96: 2301-2304.

Muller, S., Scaffidi, P., Degryse, B., Bonaldi, T., Ronfani, L., Agresti, A., Beltrame, M., and Bianchi, M.E. 2001. The double life of HMGB1 chromatin protein: Architectural factor and extracellular signal. EMBO T. 20: 4337-4340.

Myung, P.S., Clements, J.L., White, D.W., Malik, Z.A., Cowdery, J.S., Allen, L.H., Harty, J.T., Kusner, D.J., and Koretzky, G.A. 2000. In vitro and in vivo macrophage function can occur independently of SLP-76. Int. Immunol. 12: 887-897.

Ohgoh, M., Shimizu, H., Ogura, H., and Nishizawa, Y. 2000. Astroglial trophic support and neuronal cell death: Influence of cellular energy level on type of cell death induced by mitochondrial toxin in cultured rat cortical neurons. J. Neurochem. 75: 925-933.

Pieper, A.A., Brat, D.J., Krug, D.K., Watkins, C.C., Gupta, A., Blackshaw, S., Verma, A., Wang, Z.Q., and Snyder, S.H. 1999a. Poly(ADP-ribose) polymerase-deficient mice are protected from streptozotocin-induced diabetes. Proc. Natl. Acad. Sci. 96: 3059-3064.
Pieper, A.A., Verma, A., Zhang, J., and Snyder, S.H. 1999b. Poly (ADP-ribose) polymerase, nitric oxide and cell death. Trends Pharmacol. Sci. 20: 171-181.

Scaffidi, P., Misteli, T., and Bianchi, M.E. 2002. Release of chromatin protein HMGB1 by necrotic cells triggers inflammation. Nature 418: 191-195.

Scorrano, L., Oakes, S.A., Opferman, J.T., Cheng, E.H., Sorcinelli, M.D., Pozzan, T., and Korsmeyer, S.J. 2003. BAX and BAK regulation of endoplasmic reticulum $\mathrm{Ca}^{2+}$ : A control point for apoptosis. Science 300: 135-139.

Shchepina, L.A., Popova, E.N., Pletjushkina, O.Y., and Chernyak, B.V. 2002. Respiration and mitochondrial membrane potential are not required for apoptosis and anti-apoptotic action of Bcl-2 in HeLa cells. Biochemistry (Mosc) 67: 222-226.

Smith, S. 2001. The world according to PARP. Trends Biochem. Sci. 26: 174-179.

Szabo, C. and Dawson, V.L. 1998. Role of poly(ADP-ribose) synthetase in inflammation and ischaemia-reperfusion. Trends Pharmacol. Sci. 19: 287-298.

Szabo, C., Zingarelli, B., O'Connor, M., and Salzman, A.L. 1996. DNA strand breakage, activation of poly (ADP-ribose) synthetase, and cellular energy depletion are involved in the cytotoxicity of macrophages and smooth muscle cells exposed to peroxynitrite. Proc. Nat1. Acad. Sci. 93: 1753-1758.

Tsujimoto, Y., Finger, L.R., Yunis, J., Nowell, P.C., and Croce, C.M. 1984. Cloning of the chromosome breakpoint of neoplastic B cells with the $\mathrm{t}(14 ; 18)$ chromosome translocation. Science 226: 1097-1099.

Vander Heiden, M.G., Chandel, N.S., Schumacker, P.T., and Thompson, C.B. 1999. Bcl-xL prevents cell death following growth factor withdrawal by facilitating mitochondrial ATP/ADP exchange. Mol. Cell 3: 159-167.

Vousden, K.H. and Lu, X. 2002. Live or let die: The cell's response to p53. Nat. Rev. Cancer 2: 594-604.

Wang, X. 2001. The expanding role of mitochondria in apoptosis. Genes \& Dev. 15: 2922-2933.

Wang, Z.Q., Auer, B., Stingl, L., Berghammer, H., Haidacher, D., Schweiger, M., and Wagner, E.F. 1995. Mice lacking ADPRT and poly(ADP-ribosyl)ation develop normally but are susceptible to skin disease. Genes \& Dev. 9: 509-520.

Wang, Z.Q., Stingl, L., Morrison, C., Jantsch, M., Los, M., Schulze-Osthoff, K., and Wagner, E.F. 1997. PARP is important for genomic stability but dispensable in apoptosis. Genes \& Dev. 11: 2347-2358.

Wei, M.C., Zong, W.X., Cheng, E.H., Lindsten, T., Panoutsakopoulou, V., Ross, A.J., Roth, K.A., MacGregor, G.R., Thompson, C.B., and Korsmeyer, S.J. 2001. Proapoptotic BAX and BAK: A requisite gateway to mitochondrial dysfunction and death. Science 292: 727-730.

Woodgate, A., MacGibbon, G., Walton, M., and Dragunow, M. 1999. The toxicity of 6-hydroxydopamine on PC12 and P19 cells. Brain Res. Mol. Brain Res. 69: 84-92.

Yu, S.W., Wang, H., Poitras, M.F., Coombs, C., Bowers, W.J., Federoff, H.J., Poirier, G.G., Dawson, T.M., and Dawson, V.L. 2002. Mediation of poly(ADP-ribose) polymerase-1-dependent cell death by apoptosis-inducing factor. Science 297: 259-263.

Zong, W.X., Lindsten, T., Ross, A.J., MacGregor, G.R., and Thompson, C.B. 2001. BH3-only proteins that bind pro-survival Bcl-2 family members fail to induce apoptosis in the absence of Bax and Bak. Genes \& Dev. 15: 1481-1486.

Zong, W.X., Li, C., Hatzivassiliou, G., Lindsten, T., Yu, Q.C., Yuan, J., and Thompson, C.B. 2003. Bax and Bak can localize to the endoplasmic reticulum to initiate apoptosis. J. Cell Biol. 162: 59-69. 


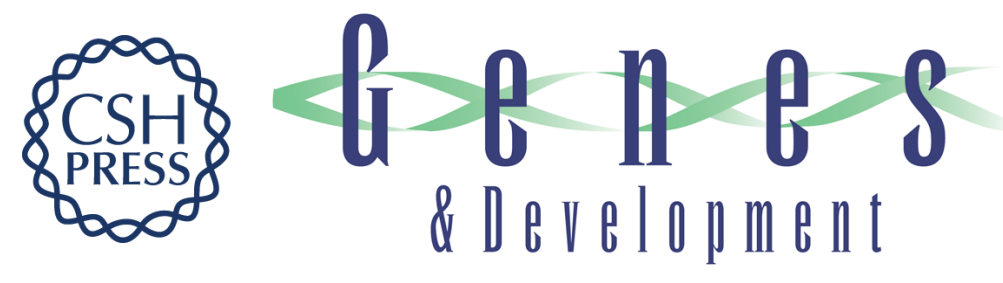

\section{Alkylating DNA damage stimulates a regulated form of necrotic cell death}

Wei-Xing Zong, Dara Ditsworth, Daniel E. Bauer, et al.

Genes Dev. 2004, 18:

Access the most recent version at doi:10.1101/gad.1199904

References

This article cites 43 articles, 17 of which can be accessed free at: http://genesdev.cshlp.org/content/18/11/1272.full.html\#ref-list-1

\section{License}

Email Alerting

Receive free email alerts when new articles cite this article - sign up in the box at the top Service right corner of the article or click here.

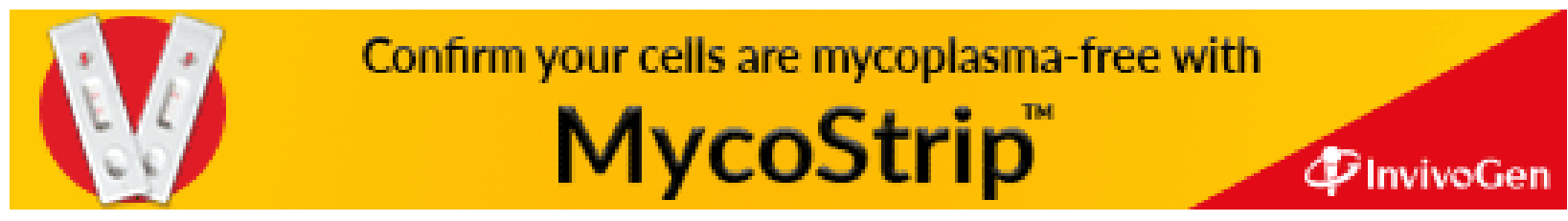

